\title{
Rehabilitation of Arthroplasty Patient During Covid-19
}

\author{
Gaurav Govil $^{1,2} \mathbb{E} \cdot$ Lavindra Tomar $^{1,3} \cdot$ Pawan Dhawan $^{1,4}$
}

Received: 10 May 2020 / Accepted: 18 May 2020 / Published online: 24 May 2020

(c) Indian Orthopaedics Association 2020

Sir,

Commentary on guidelines regarding the management of orthopaedic patients during Covid-19 in India is thoughtprovoking and an evolving process [1]. Protocol for immediate orthopaedic management has been well emphasized [1, 2]. Post-operative care and physiotherapy have been briefed but without any elaborate guidelines [1]. There is no denying the fact that rehabilitation protocol is important for recovery from orthopaedic procedures especially arthroplasty [3]. In the present pandemic, healthcare workers have been incapacitated in the conduction of their wishful activities. We feel guidelines for rehabilitation are necessary for attaining desired functional outcomes during Covid-19.

\section{Rehabilitation of Orthopaedics and Arthroplasty Patient}

Initially, in the confusion of the first few days of lockdown, there was utter chaos. The established protocols were sidelined and patients asked to care on their own with dictum being "stay home and stay safe". Patients faced additional challenges to their recovery path on discharges. Limited health care services in adjoining native areas, including no

Gaurav Govil

gauravgovil@yahoo.co.in

Lavindra Tomar

ltomar@rediffmail.com

Pawan Dhawan

pawan.msortho@gmail.com

1 Department of Orthopaedics, Max Super Speciality Hospital, 108 A, I.P. Extension, Patparganj, Delhi 110092, India

2 D-101, Sunshine Helios, Sector 78, Noida, Uttar Pradesh 201305, India

3 A-702 Vardhman Apartment, Mayur Vihar Phase 1 Extension, Delhi 110091, India

4 House No 37, Sukh Vihar, Delhi 110051, India rehabilitation services available compound the scenario [3]. The majority may respond well to the rehabilitation protocols adopted in pre-Covid era [4]. However, the fear of an uncertain period of restrictions, additional measures to safeguard from an evolving medical emergency in an elderly population will have a profound psychological impact on recovery [5]. Recurrent episodes depending on the disease load may require lockdown restrictions for the next two years. Safety comes first even when the endeavour is to provide a reasonable outcome. The induction of patient into an orthopaedic or arthroplasty programme should be a systematic team approach with the inclusion of established patient-specific home-based rehabilitation protocol. Plans that need consideration [3] are:

(a) Preoperative identification of patient home caregivers.

(b) Training them in the basic rehabilitation protocols and exercise programmes through simulation exercises, pictorial and video study material preoperatively and during hospitalization.

(c) Educate them regarding danger or red flags of orthopaedic or arthroplasty management for early and rapid response.

(d) Devices of utility required in immediate post-operative rehabilitation at home (walker, toilet chair, heat sensor, oxygen saturation probe) to be detailed.

(e) Issue an official identity card countersigned from a competent authority at discharge to facilitate an early home-based response from a healthcare provider.

(f) Early establishment of a communication link between surgeon and patient to ensure a healthy mental attitude that you are cared for and need-based solutions are available.

Physical therapy will be even more crucial in the medium to long-term response to assist the orthopaedic and arthroplasty patient to regain optimal function and to help them return to their previous level of activities [3]. National associations are well placed to support and formulate both national and local planning for a coordinated response. Lack 
of available trained healthcare providers or physiotherapist in this scenario poses a health challenge that should not be overlooked.

\section{Compliance with Ethical Standards}

Conflict of interest The authors declare that they have no conflict of interest.

Ethical standard statement This article does not contain any studies with human or animal subjects performed by any of the authors.

Informed consent For this type of study informed consent is not required.

Authors declaration All authors read and approved the final manuscript.

\section{References}

1. Neradi, D., Hooda, A., Shetty, A., Kumar, D., Salaria, A. K., \& Goni, V. (2020). Management of orthopaedic patients during
COVID-19 pandemic in India: A guide. Indian Journal of Orthopaedics, 54, 402-407. https://doi.org/10.1007/s43465-020-00122 $-6$.

2. BagariaV, Sahu D. (2020). Orthopaedics in times of COVID 19. Indian Journal of Orthopaedics, 54, 400-401. https://doi. org/10.1007/s43465-020-00123-5.

3. Editorial: A Message from the Nepal Physiotherapy Association. (2015). The role of physical therapists in the medical response team following a natural disaster: Our experience in Nepal. Journal of Orthopaedic and Sports Physical Therapy, 45(9), 644-646. https://doi.org/10.2519/jospt.2015.0108.

4. Ranawat, C. S., Ranawat, A. S., \& Mehta, A. (2003). Total knee arthroplasty rehabilitation protocol: What makes the difference? The Journal of Arthroplasty, 18(3), 27-30. https://doi. org/10.1054/arth.2003.50080.

5. Smith, T. (2017). "On their own": Social isolation, loneliness and chronic musculoskeletal pain in older adults. Quality in Ageing and Older Adults,. https://doi.org/10.1108/QAOA-03-2017-0010.

Publisher's Note Springer Nature remains neutral with regard tojurisdictional claims in published maps and institutional affiliations. 